\title{
As Guerras Mundiais e as mutações na teoria social da comunicação e dos media ${ }^{1}$
}

\section{World wars and changes in the social theory of media and communication}

\author{
Filipa Subtil
}

Doutora em Ciências Sociais pelo Instituto de Ciências Sociais da Universidade de Lisboa; Professora adjunta nos cursos de graduação e pós-graduação em Comunicação, Escola Superior de Comunicação Social, Instituto Politécnico de Lisboa, Portugal. $<$ fsubtil@escs.ipl.pt>

\section{RESUMO}

Se a guerra é a continuação da política por outros meios, então certamente que nela a comunicação, em sentido lato, esteve sempre presente e desempenhou um papel chave. As guerras não implicam apenas a violência, mas também a persuasão, a contrainformação, o convencimento e o combate ideológico. Nas guerras modernas, os media têm sido um elemento fundamental para mobilizar nações moldadas por dinâmicas de desenraizamento e desterritorialização com vista a um esforço conjunto de apoio popular à ação bélica do Estado. Este artigo incide nas transformações que a própria teoria e investigação em comunicação e media sofreram no período entre as duas Guerras Mundiais do século XX. Trata-se de um contexto histórico decisivo para compreender como a institucionalização do campo da comunicação num país central como os EUA ocorreu em condições sociais e políticas que contribuíram para o seu perfil epistemológico, posições teóricas e para a configuração do poder no próprio sistema científico universitário, cujas repercussões continuam a fazer-se sentir de diversas e complexas formas.

Palavras-chave: Guerras Mundiais. Teoria social dos media. Propaganda.

\begin{abstract}
If war is the continuation of politics by other means, there is no doubt that communication was always a key part of it. Wars involve not only violence, but also persuasion, counter-information, ideological conviction and confrontation. In modern wars, the media have played a fundamental part in mobilizing nations shaped by the dynamics of uprooting and de-territorialization into collective efforts designed to achieve popular support the State's war actions. This paper discusses the change that theory and research in communication and media underwent in the period between the two world wars of the twentieth century. This is a historical context that is crucial for an understanding of how the institutionalization of the field of communication in a major country like the US took place in a social and political context which shaped its epistemology and theoretical positioning, and contributed to the way power was established in the system of research in the universities. Its repercussions are still being felt today in diverse and complex ways.
\end{abstract}

Keywords: World wars. Social theory of media. Propaganda.

1 Uma versão mais curta deste texto foi apresentada, a convite da direcção da Intercom, no XXXVII Congresso Brasileiro de Ciências da Comunicação "Comunicação: Guerra \& Paz" (Foz de Iguaçu, 2014), no XXXVII Ciclo de Estudos de Comunicação (CECOM), mesa 3 "Narrativas de Guerra". Este texto beneficiou da leitura atenta e dos comentários de José Luís Garcia, Hermínio Martins e João Tiago Proença, a quem muito agradeço. 
Usando os termos de James W. Carey, as teorias da comunicação são quer mapas da realidade, quer mapas para a realidade. Sucintamente, tal significa que os mapas de estudo da comunicação, por um lado, guiam-nos no entendimento do universo comunicacional, e, por outro, contribuem para forjar e erguer diversas realidades comunicacionais e, por consequência, culturas e sociedades diferentes (Carey, 2009; Subtil, 2014). A alteração dos mapas do estudo da comunicação não implica apenas transformações de ordem epistemológica, mas também teórica e política.

Este texto centra-se nas mutações da teoria e da pesquisa em comunicação e media no decurso das Guerras Mundiais e toma como pressuposto uma das grandes aquisições da filosofia e da sociologia da ciência, da segunda metade do século XX: a relação entre valores epistémicos internos à actividade científica (avaliação cognitiva das teorias e hipóteses) e valores externos (éticos, sociais e econômicos presentes em etapas da pesquisa, tais como a adopção da estratégia de investigação, a divulgação dos resultados e a sua aplicação) subjacentes às acções dos cientistas e implícitos nos contextos institucionais em que intervêm, valores muito relevantes nas escolhas efectivas dos pesquisadores e nos resultados científicos alcançados. A discussão a que procedemos de seguida procura sustentar como o contexto entre as Guerras Mundiais estimulou alterações nos estudos e pesquisas da comunicação até então prevalecentes, tendo permitido desenvolver outras teorias e estratégias de investigação que se vieram a afigurar em aspectos fulcrais muito divergentes das anteriores.

\section{Problemas e perspectivas do estudo da comunicação e dos media nos Estados Unidos da América}

O estudo da comunicação e dos media começou a manifestar-se com certo destaque nos Estados Unidos da América (EUA), na Universidade de Chicago, sob o estímulo e o impacto do movimento Progressista de reforma da passagem do século XIX para o XX. Os fins, as condições e os valores dos progressistas foram um esteio para concepções da comunicação e dos media (sobretudo a imprensa, mas também o cinema, anos mais tarde) que, entre 1930 e 1960, acabaram por ser profundamente modificadas na academia norteamericana, onde a Universidade de Columbia veio desempenhar um papel importante.

Decorrente dos efeitos da segunda revolução industrial, do enorme crescimento das cidades, da recepção de grandes contingentes de imigrantes e de mudanças profundas na vida pública, vários teóricos do Departamento de 
Sociologia e Antropologia, da Universidade de Chicago, ao mesmo tempo que desenvolveram pesquisas sobre os temas da cidade, da ecologia humana, da imigração, das relações étnicas, da delinquência e do controlo social, dedicaram uma especial atenção aos tópicos da comunicação pública, do jornalismo e da comunicação intersubjectiva.

Desde a emergência da sociologia e da antropologia nos EUA, a comunicação e o jornalismo foram uma presença constante na teoria social norte-americana. Encontramos estas preocupações em Albion Small, Edward Ross, William Sumner, John Dewey, Charles H. Cooley, George H. Mead, William I. Thomas, Florian Znaniecki e Robert E. Park, este último considerado por muitos o primeiro sociólogo dos media (Lopez-Escobar, 2012; Torregosa, SerranoPuche, Algarra, 2012; Subtil e Garcia, 2010; Berganza, 2008/2000). Pode afirmarse que a sociologia norte-americana foi pioneira na abordagem daqueles temas, embora saibamos que tanto nessa disciplina como na economia política europeias vários foram os teóricos que se interessaram por eles. Na sociologia, importa recordar, na França, os contributos de Gabriel Tarde (1991) sobre multidão, públicos e opinião; na Alemanha, as notas de Max Weber (2006) sobre tópicos como a urgência de instituir uma sociologia do jornalismo e a importância da comunicação política nas sociedades do início do século XX; e Ferdinand Tönnies (2006), no seu livro sobre crítica da opinião pública. Já na economia política alemã, os trabalhos de Karl Bücher, Karl Knies, Albert Schäffle são referências importantes (Hardt, 2001).

Com efeito, foram os teóricos da Escola de Chicago do pensamento social que colocaram a comunicação e a vida subjectiva no âmago da compreensão do ser humano e da explicação social, acrescentando-lhe ainda uma dimensão normativa. Estes autores pensaram a comunicação quer como um fundamento moral da vida colectiva, quer uma condição da democracia como ideal social. Persuadidos por esta perspectiva, acreditaram nas possibilidades que as tecnologias da comunicação moderna, isto é, a imprensa e depois a rádio e o cinema, abriram no processo de democratização e progresso social.

Sintetizemos as suas ideias a este respeito: 1) O conceito de comunicação foi utilizado como sinónimo de conexão, de ligação humana, tendo colocado a comunicação interpessoal no cerne da formação e transformação da personalidade. A comunicação permitia a socialização e desencadeava a formação do self, distanciando-se das interpretações instintivas do comportamento humano, do darwinismo e do behaviorismo. Esta pista abriu o caminho para uma corrente de investigação que, como se sabe, Herbert 
Blumer designou por interaccionismo simbólico². Tal conceito de comunicação funda-se numa perspectiva trans-accional da actividade simbólica dos indivíduos, que ocorre numa pluralidade de níveis articulados, desde a dimensão interpessoal, à intergrupal e às que são coextensivas à sociedade global; 2) A comunicação foi considerada a chave para a solução potencial dos problemas sociais das sociedades urbanas, cosmopolitas e industrializadas. Os conceitos de comunicação e comunidade foram utilizados como discurso de protesto e resolução das antinomias induzidas pela industrialização avançada e o crescimento enorme das cidades, mas também como fórmula para que estes elementos tomassem contornos mais humanos e mais consentâneos com um modo de vida democrático (Peters e Simonson, 2004); 3) Procuraram compreender o lugar dos media na política democrática. Foram pioneiros do estudo dos jornais, da opinião pública, das infra-estruturas e fluxos de transporte e comunicação, das redes e da interacção grupal. O seu compromisso com a reforma social, porém, tendeu a sobrepor-se ao estudo concreto da forma como a comunicação e os media se estavam a desenvolver. Caracterizaramse por uma aproximação demasiado estreita entre ideais e realidades, tendo sido permeáveis a ilusões sobre a democracia e à possibilidade de consenso racional sobre as grandes decisões societais, bem como à paz como norma imanente da humanidade. A sua negligência no que respeita a factores como conflito, autoridade e dominação contribuiu para perderem de vista o lado mais sombrio da realidade da comunicação moderna, embora dele tivessem uma certa consciência.

Como se afirmou anteriormente, no período entre as Guerras Mundiais, esta perspectiva e tipo de problematização foi quase completamente ofuscado, ao mesmo tempo que ocorria a institucionalização de um campo de estudo e investigação específico em comunicação e media. Referimo-nos ao surgimento da chamada mass communication research, sob a égide do Bureau of Applied Social Sciences, da Universidade da Columbia e da Fundação Rockefeller. O contexto bélico das Guerras Mundiais, os cenários institucionais que enquadraram a pesquisa em comunicação e a axiologia em que se alicerçou uma parte importante das investigações vieram secundarizar as preocupações, os valores e tipos de pesquisa em comunicação que tinham sido desenvolvidas pela geração de progressistas norte-americanos.

2 Vale a pena recordar que o termo interaccionismo simbólico foi cunhado por Blumer num artigo publicado em Man and Society, editado por Emerson P. Schmidt, em 1937. 
Todavia, não é de negligenciar a existência de determinadas linhas de continuidade, tais como a ênfase na pesquisa de campo e o lastro do darwinismo social, bem detectáveis na figura chave de Harold D. Lasswell. Este fez a sua formação e parte do percurso académico (até 1938) na Universidade de Chicago e tornou-se um dos expoentes da formação do campo da comunicação e das teorias dominantes que sucederam às dos teóricos progressistas. Tenha-se em consideração que, por um lado, as ciências sociais são caracteristicamente marcadas pela controvérsia interna e pela pluralidade epistemológica, teórica e metodológica e, por outro, que não é despropositado sustentar algum cepticismo para com noções de absoluta descontinuidade quanto à mudança cognitiva nas ciências. Vale a pena, pois, fazer uma breve referência ao trabalho de Lasswell, já que de algum modo operou a ligação entre a Escola de Chicago do pensamento social no âmbito da comunicação e do jornalismo e as perspectivas teóricas que se tornaram depois dominantes entre as duas Grandes Guerras. Tendo chegado, em 1918, à Universidade de Chicago para estudar economia, ingressa, em 1922, no Departamento de Ciência Política, à época presidido por Charles E. Merriam³, que viria a ser o orientador da sua tese de doutoramento. Deve-se a Merriam a sua aproximação ao universo dos estudos de comunicação, mais concretamente ao tema da propaganda, do qual se tornará um dos maiores especialistas. Merriam era já uma figura de destaque no meio académico, onde tinha levado a cabo a consolidação e projecção do departamento de ciência política, mas também na vida pública, com cargos de relevo na política local de Chicago. Tinha uma forte convicção de que as teorias sobre os processos políticos deviam estar em estreita relação com a actividade política concreta. Exerceu funções como chefe de propaganda dos EUA, em Roma, durante a I Guerra Mundial, analisando os efeitos e o conteúdo da propaganda norteamericana na Itália. Lasswell interessou-se pelo tema da propaganda seduzido pela importância que Merriam dava a esse tópico e à sua relação com a moral e a formação cívica na explicação do comportamento político (Varão, 2012). Em 1926, defende a tese de doutoramento intitulada Propaganda technique in the World War, prosseguindo as visões de Merriam sobre a ciência política4.

Como bem salienta Varão, a quem devemos um estudo de fundo em língua portuguesa sobre o teórico norte-americano, logo no primeiro capítulo daquele

3 Sobre a influência de Merriam no pensamento de Lasswell sobre propaganda, ver Varão (2013).

4 A tese concretiza o carácter científico (no sentido positivista) que o seu orientador defendia para a ciência política, apoiando uma abordagem da política que estabelecesse relações com a pesquisa de campo, ao mesmo tempo que considerava que o comportamento político era o principal foco de estudo deste domínio científico. 
trabalho, que viria a ser publicado um ano mais tarde, Lasswell explicitou que, mais do que fazer a história da propaganda, o seu intuito era "escrever uma teoria explícita e geral das estratégias de propaganda utilizadas na I Guerra Mundial" (Varão, 2012, p. 137). Para Lasswell, a propaganda era "o controlo da opinião pública através de símbolos significativos, ou mais concretamente por histórias, boatos, relatórios, retratos e outras formas de comunicação" (1938, p. 8-9). Mais do que condenar a propaganda, concebia-a como um conjunto de técnicas neutrais que podiam ser utilizadas para o bem ou para o mal. Em 1940, Lasswell aceita liderar a Experimental Division for the Study of War Time Communications, da Biblioteca do Congresso, em Washington. Esta entidade foi financiada pela Fundação Rockefeller e possibilitou o aprofundamento dos seus estudos sobre a propaganda. Deve-se-lhe ainda a invenção da expressão seringa/agulha hipodérmica para denominar a influência dos meios de comunicação de massas nas audiências passivas. E, em 1948, elabora a célebre pergunta-programa "Quem? Diz o quê? Por que canal? A quem? E com que efeitos?", interrogações que tiveram um papel fulcral no desenvolvimento e orientação do campo de estudos da comunicação nos EUA.

O universo de pensamento dos progressistas da Escola de Chicago, traçado anteriormente, veio a ser de tal forma descurado que a emergência da mass communication research surge na maioria dos principais manuais de história e investigação em comunicação e media como a "narrativa standard" (e até única) neste âmbito de estudos (Carey, 1997, p. 24). É importante frisar que o corte que a perspectiva efectuou com a tradição anterior surge também conjugado com um novo sistema técnico, económico e empresarial de informação e cultura que abrangia a imprensa de massas, a radiodifusão, o cinema e posteriormente a televisão.

Esta mutação tecnológica articulou-se ainda com outros factores de ordem social, comercial, cultural e política, como sejam a importância crescente do consumo, da publicidade, da esfera do entretenimento e a utilização por parte do poder político das técnicas de informação para o convencimento e mobilização dos indivíduos em prol de fins perseguidos pelo poder; no âmbito das estratégias de investigação, realce-se o uso de metodologias quantitativas com base em sondagens e inquéritos de opinião. Essas estratégias adequaramse às solicitações do Estado norte-americano e da indústria dos media, que empreenderam esforços significativos no sentido de conhecer os seus públicos, a eficácia persuasiva da publicidade e a adesão activa às mensagens políticas.

Os estudos empírico-quantitativos, já em franca expansão nas ciências sociais nesse período, começaram a fornecer um certo tipo de conhecimento 
sobre as principais mudanças dos processos comunicativos implementados pela rádio e pela televisão: por um lado, a comunicação à distância e sem presença física, por outro, o seu poder de influência num fenómeno social, o consumo massivo, comercial e largamente atomizado dos meios.

\section{A indistinção entre verdade e mentira: o caso da propaganda moderna}

Atéà guerra de 1914-1918,os confrontos militares, a menosqueocorressem próximo das vilas e cidades, envolviam sobretudo os exércitos, lutando estes com certo distanciamento das populações civis. A I Guerra Mundial foi um conflito militar de larga escala que pressupôs o comprometimento e a mobilização do conjunto de cada nação em redor de um objectivo comum - combater o inimigo. Para alcançar estes propósitos, foi crucial promover sentimentos e lealdades, recrutar soldados, induzir ódio ao inimigo, amor à pátria, manter a moral das populações, em suma, mobilizar uma sociedade já estruturada pelos valores modernos do desenraizamento e da desterritorialização para um esforço conjunto capaz de apoiar a acção bélica do Estado. A este propósito, é valiosa a alusão ao escritor português Aquilino Ribeiro no seu diário sobre os dois primeiros anos da I Guerra Mundial, escrito em Paris, intitulado $E$ a Guerra. Afirmava então que, quando o rei deixou de estar presente no cenário de guerra, acompanhando a introdução das armas de fogo nos exércitos, o problema passou a ser fazer com que o cidadão marchasse persuadido de que, fora do alcance do seu líder político, fazia a guerra pelo seu alvitre e no seu bom interesse (Ribeiro, 2014).

Em sociedades em que os sistemas de controlo social informal se encontravam modificados, tornou-se tentador para os mecanismos do poder fazer uso, em situações de crise, de alguns dos meios que emergiram nas sociedades modernas de estímulo à ligação e à mobilização social. Os mass media, cada vez mais acessíveis a grande parte da população, puderam assim converter-se nos principais difusores em larga escala de emoções, mensagens e fervores, que sublimavam os que eram considerados os altos desígnios da nação e apelavam aos sentimentos de comunhão.

Entre esses meios dirigidos a vincular e a mobilizar a população, para além do papel da instrução pública e da situação mais extrema de incorporação à força de sectores da sociedade, incluiram-se a generalização da utilização sistemática de tecnologias e dispositivos informacionais que procuravam ora seduzir, ora a obediência entusiasta, ora ainda a violência psíquica. 
A propaganda pode ser definida como uma estratégia de manipulação da opinião de forma tal que os indivíduos sejam convencidos a estar simultaneamente em concordância com ela e sem capacidade de realizar outra opção. Em termos epistemológicos, as mensagens situam-se num campo de indistinção entre a verdade e a mentira, e no seu caso mais extremo têm mesmo como objectivo falsificar, mas de tal modo que os indivíduos não percebam que estão a ser vítimas do engano.

As guerras mundiais do século XX ofereceram as condições adequadas à equivalência entre propaganda e produção mediática da mentira. "Quando a guerra é declarada, a verdade é a primeira vítima", como bem afirmou Arthur Ponsonby, autor do conhecido decálogo da propaganda de guerra e do livro Falsewood in Wartime. Propaganda Lies of the First World War (1991). A propaganda é, por conseguinte, o contrário da argumentação, da troca de ideias, da manifestação livre de juízos conscientes, isto é, das formas de comunicação que tinham atraído os teóricos progressistas do período anterior da passagem do século XIX para o século XX.

Talvez se possa afirmar que neste quadro de fortalecimento dos poderes de Estado e das tecnologias se entrou na era da manipulação industrial e tecnológica da opinião em larga escala, onde a mentira tem um lugar destacado. Importa notar que não se trata de uma afirmação leviana, já que a questão da mentira política é um problema central de filosofia política presente no pensamento desde Platão a Maquiavel e até aos nossos dias. A interrogação que deve ser formulada a este respeito é a seguinte: dever-se-á, mesmo que para bem do povo, esconder-Ihe a verdade ou obstaculizar-Ihe a sua procura? Ou de outro modo: pode o constrangimento mental ou a mentira serem considerados meios adequados quando justificados por um suposto bom fim? De facto, como se verá, não são apenas os regimes políticos totalitários, ditatoriais e autoritários - já para não falar do mundo comercial e corporativo - que fizeram uso (e continuam a fazer) da propaganda para a adesão não consciente aos seus objectivos.

Os meios de produção industrial da obediência mental e da manipulação da palavra e da opinião tinham já sido testados pelo sector privado, que investiu fortemente na sofisticação e proliferação de planos de construção artificial de consensos. Tal tarefa foi levada a efeito, nos começos dessa década nos EUA, pelos criadores da nova actividade das relações públicas, onde sobressai o 
nome de Edward Bernays ${ }^{5}$, um dos membros do Committee on Public Information (CPI), também conhecido como Creel Committee, nome do jornalista que o dirigiu, George Creel. Criado em 1917 pelo então presidente Woodrow Wilson ${ }^{6}$ e composto por jornalistas, especialistas de opinião pública e militares, este comité foi responsável pela supervisão de toda a máquina de propaganda e censura do governo norte-americano durante a I Guerra Mundial (Mattelart, 2000), tendo-se tornado num verdadeiro laboratório de propaganda moderna. A missão desta agência governamental era coordenar a propaganda, não no sentido que os alemães a definiam e praticavam, mas na antiga acepção da palavra "propagação da fé".

O Creel Commitee não só elaborou meticulosamente novas histórias e milhares de comunicados de imprensa, que foram publicados em jornais, cartazes, folhetos, murais, fotografias, enviados pelos fios do telégrafo, emitidos pela rádio e projectados nas salas de cinema, como monitorizou de perto os media com o intuito de confirmar a sua adesão à causa nacional. $O$ programa de propaganda do CPI estendeu-se também à instrução pública. A sua Divisão de Educação produziu, imprimiu e distribuiu mais de 75 milhões de materiais destinados aos estudantes de todos os níveis de ensino. Muita desta documentação foi elaborada por académicos contratados por Washington para desenvolver conteúdos para as campanhas de propaganda. O CPI converteuse numa organização burocrática massiva que conseguiu, num curto espaço de tempo - cerca de 6 meses -, transformar uma população pacífica numa população histérica, fomentadora da guerra e que, sob a confecção mediática da aura quase religiosa da nação norte-americana, queria aniquilar tudo o que fosse alemão, ir para os campos de batalha e salvar o mundo'.

No final da I Guerra Mundial, a propaganda começou a ser seriamente questionada (em particular as técnicas utilizadas pelo CPI), o que desencadeou um amplo debate na sociedade norte-americana sobre a legitimidade moral da utilização dessas técnicas de manipulação em sociedades democráticas.

5 Para uma breve, mas elucidativa análise do papel de Bernays na legitimação do papel da propaganda ao serviço do governo e do mundo empresarial, ver Baillargeon (2007) e Dortier (2011). Em língua portuguesa, ver Rüdiger (2014).

6 Wilson foi pioneiro no reconhecimento da importância da investigação em comunicação para compreender as dimensões comunicativas na produção da decisão política. Sobre o papel que teve na reflexão sobre a importância da investigação em comunicação no mundo da policy-making, mas também na concretização prática destas ideias enquanto presidente dos EUA, ver Braman (2003, p. 3638).

7 Para uma análise detalhada do papel do CPI, ver Glander (2009, p. 4-16) e Baillargeon (2007, p. 1014).

8 Note-se, todavia, que até à I Guerra Mundial, a conotação da expressão propaganda foi sempre positiva. Originalmente, o seu significado encontra-se associado à Igreja Católica, à Congregação da Propaganda Fide (Sagrada Congregação para a Propagação da Fé), organismo que tinha como objectivo 
A discussão polarizou-se em torno de duas posições. Por um lado, os que defenderam a tese da utilização controlada da propaganda, por ser o meio mais eficaz para o controlo e coesão social das populações em tempo de guerra, ao mesmo tempo que facilitaria a obtenção de consensos sociais em prol da ideia de "segurança nacional" e da decisão do governo em participar no conflito. Por outro, os que se opunham à utilização de qualquer tipo de propaganda, por ser uma forma indigna de estratégia de persuasão política. Este último grupo formou uma sensibilidade que se transformou rapidamente num foco de contestação congregador de vários intelectuais e instâncias de relevo na sociedade norte-americana, de que são exemplos Dewey e a Associação Nacional dos Educadores ${ }^{9}$. Esta associação, a que podemos acrescentar outras como o Institut for Propaganda e o National Council for Social Sciences ${ }^{10}$, advogou uma aposta séria num programa de educação cívica, capaz de formar cidadãos intelectualmente autónomos, capacitados para formular juízos independentes.

Dewey, em coerência com a perspectiva dos progressistas da Escola de Chicago do pensamento social e apoiante do papel da educação cívica, enfatizou que a forma mais eficaz de resistência à propaganda era viver no seio de uma comunidade com uma vida autêntica e plena. Na ausência desta estrutura, a acção das tecnologias de comunicação massiva tenderia a promover a conformidade e a enfraquecer a qualidade da vida comunitária. Embora tenha perecido com o início da II Guerra Mundial, este movimento de contestação manteve-se como uma resposta contundente às mudanças que os meios de comunicação tinham desencadeado na sociedade norte-americana (Glander, 2009).

As inquietações da sociedade civil dos EUA são parte de uma preocupação que se estende, em diversos períodos marcantes, a vários círculos de investigação sobre o novo fenómeno da acção organizada da persuasãoe do condicionamento

difundir a fé católica pelo mundo e, implicitamente, combater a acção da Reforma. A criação desta entidade, em 1622, pelo Papa Gregório XV, revestiu-se de alguma importância visto ter sido com ela que nasceu o termo que designa o fenómeno. Também na política secular, e na sequência da Revolução Francesa, a propaganda passou a resultar da combinação entre a intenção do propagandista e a necessidade real daquilo que é propagandeado. O seu objectivo deveria ser satisfazer uma necessidade e não exprimir um mero desejo de poder por parte do propagandista. O mesmo irá ocorrer durante a Revolução Russa, com Lenine e os bolcheviques, em que o termo propaganda tinha um sentido positivo. Para uma análise mais detalhada sobre história da propaganda, ver Ellul (1967). Especificamente sobre propaganda política, ver também Domenach (1975).

9 A Associação Nacional de Educadores apelava aos pais para que estivessem atentos às múltiplas formas de propaganda que tinham como alvo fácil e desprotegido os jovens, bem como para a urgência de implementar um programa de análise crítica das mensagens que os leve desenvolver o seu sentido crítico de forma a estarem melhor preparados para resistir às acções insidiosas da propaganda.

10 Estas entidades foram responsaveis pela elaboração de materiais didácticos com conteúdos antipropaganda. 
psicológico através dos mass media. Recorde-se que, também sob o contexto da I Guerra Mundial e da importância que teve no deflagrar da Revolução Russa, de 1917, Lenine dera já passos decisivos no âmbito das novas possibilidades do convencimento político, compreendendo a actividade de influência como uma acção coordenada capaz de fazer a ligação entre a planificação dos fins políticos e a mobilização das massas"1. É sob este pano de fundo que a análise da propaganda se constituiu como o primeiro tópico de investigação empírica de grande relevância ${ }^{12}$ no qual os trabalhos de Lasswell pontificaram, e a que se juntaram posteriormente três outras linhas de investigação: a pesquisa sobre opinião pública (além de Lasswell, Walter Lippmann), os estudos psicológicos de análise dos media (realizados pelo Payne Fund) e a marketing research (com Paul Lazarsfeld), para usar uma expressão de Daniel Czitrom (1982) ${ }^{13}$.

Enquanto na esfera pública norte-americana se esgrimiam argumentos contra e a favor da propaganda, no terreno político e militar, os acontecimentos da I Guerra Mundial revelaram-se indispensáveis para perceber que, a partir de então, nenhum governo, mesmo em tempo de paz, poderia negligenciar a importância estratégica dos media e da psicologia para fins de influência, convencimento, manipulação, desinformação e combate ideológico. Esta é, porventura, uma das grandes descobertas desse período relativa ao exercício do poder. Daí em diante, o poder político tenderá a não prescindir das possibilidades de persuasão disponibilizadas pelas novas formas de mediação técnica da comunicação, o cinema, a fotografia, o rádio e, décadas mais tarde, a televisão, meios cada vez mais penetrantes tanto para informar como para condicionar a

11 O governo saído da Revolução de Outubro encontrava-se numa situação que compelia ao emprego da propaganda, considerada fundamental para conduzir a guerra contra os inimigos e para convencer o povo a apoiar os esforços revolucionários. Foi utilizada como uma das principais armas para a consolidação do regime. E como o marxismo pode ter uma dimensão doutrinária, a propaganda teve de ser ideológica e doutrinal. O objectivo principal era educar o povo quer intelectualmente (aceitação de uma doutrina e aceder a uma certa interpretação dos factos), quer na prática (acção, envolvimento). Ainda porque o marxismo implicava a unidade entre o pensamento e a praxis, este era o único caminho possível e desejável. É a dupla conjugação destes elementos que corresponde à actividade daquilo que ficou conhecido como Agit Prop.

12 Sobre a investigação em propaganda entre os anos de 1920 e 1940, nos EUA, ver Cmiel (1996, p. 88-107 maxime p. 89-92) e Sproule (1987, p. 60-87; 1989, p. 225-246; 1997, p. 129-261).

13 A preocupação com o fenómeno da propaganda é compreensível num período em que Adolf Hitler e Joseph P. Goebbels se vão tornar, pouco tempo depois, em expoentes máximos da importância vital do universo manipulável dos conteúdos e do campo simbólico da comunicação política. Todavia, tendo em consideração a importância da propaganda para os regimes de democracia representativa durante as Guerras Mundiais, é totalmente erróneo circunscrever aos exemplos extremos a relação entre meios de massa e propaganda. Existem muitas indicações, tal como o trabalho de Ellul (2014) enfatizou, sobre a persistência de formas de convencimento orientadas para a dominação política (em particular, a dominação imperial, dando o exemplo do Império Romano), bem como sobre a surpreendente articulação entre modalidades comunicativas de condicionamento psicológico (via publicidade) e o consumismo das sociedades do pós-II Guerra Mundial. Para uma leitura actualizada sobre Ellul e a propaganda, ver Alves (2014). 
opinião das populações. A eficácia demonstrada pela comunicação de massas contribuiu para alcançar um assentimento alargado sobre a importância do trabalho de orientação ideológica na manutenção da moral das populações e das tropas, e inclusivamente na preservação da cultura democrática, mas também, em caso de necessidade, do seu contrário.

$\mathrm{Na}$ reflexão teórica começa a vingar o princípio de que o Estado deve possuir meios adequados para organizar, orientar e administrar a opinião pública. Juntamente com Lasswell, Walter Lippmann é um interveniente central nesta orientação. Apesar das diferenças, ambos tendiam a sustentar que o papel dos especialistas era moldar a forma de pensar das pessoas, gerindo as quantidades precisas de informação e censura. Muitas destas propostas constituíram-se em guias de um novo modo de fazer política, tendo dado alento a que a discussão política se tenha tornado numa actividade profissional praticada, em grande medida, por corpos especializados, tais como jornalistas, publicitários, relações públicas, profissionais do marketing, etc. A propaganda foi instituída como parte dos mecanismos de poder, quer da política interna, quer externa. A política transformou-se em policy making, em elaboração "científica" e em tomada de decisão sobre cenários alternativos de problemas isolados.

Lippmann foi realmente uma figura crucial neste âmbito, tendo sido conselheiro do presidente Wilson, e um dos principais teóricos da temática da opinião pública, a partir do seu livro, de 1922, Public Opinion. Nesta obra, Lippmann trabalha com algumas das principais dicotomias das ciências sociais, como razão/desejo, factos/ficção, objectivo/subjectivo, conjugando-as com os temas principais da comunicação de massas: as dificuldades da profissão de jornalista em pautar-se pela objectividade, o poder de distorção dos símbolos e o carácter instável da opinião das massas. O pensamento de Lippmann abriu o caminho à deslocação da problemática dos media, antes ligada às condições de liberdade necessárias para garantir uma informação fidedigna, para o questionamento da natureza das notícias e do seu enquadramento, para os aspectos psicológicos da audiência e a sua relação com a vida moderna.

Lippmann defendeu que uma verdadeira opinião pública só existe quando os espíritos individuais, que formam o público, possuem uma representação tida como correcta do mundo. Esta não é fornecida, ao contrário do que se poderia supor, pelas notícias. Na sua opinião, as notícias não representam a realidade e não têm qualquer correspondência com a verdade, quanto muito, assinalam que algo está a acontecer. A maior parte das vezes, limitam-se a fornecer fotografias manipuladas e pseudo-realidades. Segundo Lippmann, as notícias só se aproximam da realidade quando o que está em causa é redutível a dados 
quantificáveis: nascimentos, mortes, decisões judiciais, resultados eleitorais, transacções comerciais, etc. As notícias reduziriam as questões controversas e de maior complexidade a meros estereótipos. Num sentido diferente ao da tradição representada por Dewey, empenhada com as potencialidades reformadoras da imprensa e a transparência da comunicação, a proposta de Lippmann para assegurar a formação de uma opinião pública supostamente esclarecida requeria a constituição de equipas de peritos independentes capazes de reduzir os paradoxos da realidade a quadros estatísticos. Esta seria a condição para que os jornais informassem a opinião pública ${ }^{14}$. Public Opinion tornou-se numa referência clássica no ensino do jornalismo nos EUA, tendo exercido influência em Lasswell, que pode ser detectada em Propaganda technique in the World War (1927), considerada a obra fundadora da mass communication research. No início dos anos 1920, estavam inauguradas as estratégias de formação da opinião pública, apelidadas por Lippmann de "fabricação do consentimento" e por Lasswell de "gestão governamental das opiniões".

No campo de conhecimento que ficou conhecido como "estudo dos efeitos", entre 1929 e 1932, foi levado a cabo um dos projectos de investigação empírica mais consistentes em comunicação de massas, um vasto programa multidisciplinar, cujo propósito era analisar a influência do cinema nas crianças, desenvolvido pelo Motion Picture Research Council, financiado pelo Payne Fund e realizado por professores, psicólogos e sociólogos. Os treze estudos centraram-se em três categorias principais de análise: conteúdo dos filmes, composição da audiência e efeitos nas crianças. A metodologia foi-se adaptando à especificidade de cada pesquisa: para determinar as categorias de conteúdo dos filmes, recorreu-se à análise qualitativa; para determinar as audiências que assistiam aos filmes, utilizaram-se censos e dados de inquéritos; para a medição dos efeitos, os investigadores socorreram-se de design experimental, questionários, estudos de caso e entrevistas; e para medir o estímulo emocional serviram-se de técnicas laboratoriais. As primeiras conclusões apontavam para a influência directa, imediata e generalizada do cinema nas crianças. Todavia, com a sofisticação da análise, estas ideias deixaram de ser sustentáveis, nomeadamente quando o objecto da investigação eram outros meios e outro público. As conclusões destas pesquisas desencadearam sentimentos de

14 A polarização entre Dewey e Lippmann tem-se mantido como um tema aberto a novas interpretações. Recentemente, a propósito das posições de James W. Carey sobre o debate entre Dewey e Lippmann, em que Carey se coloca in lato sensu ao lado de Dewey (1997), John D. Peters (1989), Carl Bybee (1999), Michael Schudson (2008), Sue Jansen (2008), Chris Russill (2008, p. $478-504$ maxime p. 488-495) e, em Portugal, Filipe Carreira da Silva (2004) sentiram-se atraídos por este tópico e escreveram reflexões que merecem atenção. 
apreensão sobre o impacto negativo em termos de uniformização cultural, provocado por meios de sedução que se consideravam poderosos, embora ao mesmo tempo se tenham multiplicado as expectativas ligadas ao seu papel na democratização cultural (Proulx, 2001)'15.

Os desenvolvimentos das décadas de 1930 e 1940, em especial o exemplo da sofisticada prática propagandística alemã orquestrada por Hitler ${ }^{16}$ e Goebbels ${ }^{17}$, tiveram como resposta por parte do governo dos EUA, presidido então por Franklyn D. Roosevelt, a utilização, pela primeira vez, de métodos de inquirição dos públicos, tais como barómetros, sondagens de opinião, orquestração de campanhas, intervenções mediáticas programadas, etc., embora o sector privado os utilizasse há algum tempo. Durante este período, a investigação sobre meios de comunicação desenvolveu-se sobretudo no Office of Radio Research da Universidade de Princeton e era largamente financiada por fundações (Fundação Rockefeller) e redes de radiodifusão (Glander, 2009).

Note-se que, apesar de não ser inédito, o financiamento por parte do governo norte-americano não era ainda uma prática sistemática nas universidades. Entretanto, as acções de propaganda governamental para o exterior, como a criação da rádio governamental Voice of America (1942)18, foram uma contra-ofensiva às emissões radiofónicas do III Reich, dirigidas às numerosas comunidades germânicas residentes nos EUA. Durante este período chegaram vários grupos de intelectuais judeus que fugiam à perseguição do regime nazi. Entre eles, destacam-se personalidades que virão a ter uma presença marcante no domínio dos estudos de comunicação de massas e da indústria cultural, como Kurt Lewin, Paul Lazarsfeld e os marxistas da Escola de Frankfurt, Max Horkheimer, Herbert Marcuse, Theodor Adorno, Leo Lowenthal, entre outros (Eadie, 2008). Importa ter presente que, neste período, a comunidade imigrante alemã nos EUA era uma das mais numerosas (cerca de 20 milhões, entre nascidos na Alemanha e seus descendentes) e possuía os seus próprios jornais. Robert $\mathrm{E}$.

15 Blumer foi co-autor (com Philip Hauser) de dois estudos comissariados pelo Payne Fund sobre o significado social do cinema: Movies and Conduct e Movies, Delinquency, and Crime, ambos publicados em 1933. Através do método biográfico, convidou jovens das escolas e das prisões a escrever movie autobiographies que reflectissem a influência que os filmes tinham nas suas acções ou atitudes quotidianas. Concluiu que os jovens aprendiam imenso através dos filmes - desde atitudes mais genéricas perante a vida, a escolha dos estilos de penteado, beijar e até roubar uma carteira. Nas décadas seguintes, Blumer prosseguiu a reflexão sobre os efeitos dos mass media (1998a) e a opinião pública (1998b).

16 Sobre a "violência psíquica" perpetrada por Hitler ao povo alemão, ver Tchakhotine (1985).

17 Leonard W. Doob, numa análise minuciosa a um documento com cerca de 6800 páginas, da autoria de Goebbels, escrito em forma de diário, sintetiza os princípios propagandísticos do Ministro da Propaganda de Hitler (1986).

18 Para uma história da estação de rádio Voice of America, ver Heil (2003, maxime p. 32-57). 
Park, na sua investigação sobre a imprensa imigrante nos EUA, da qual resultaria um livro publicado em 1922, refere a existência, nesta década, de centenas de jornais em língua alemã, que os norte-americanos não conseguiam ler. Nestas publicações encontravam-se diversas orientações ideológicas antagónicas ao regime democrático-liberal norte-americano, umas pró-regime hitleriano, outras pró-comunistas de vários quadrantes e ainda anarquistas (Park, 1922).

Foi neste contexto amplo que se constituiu o Rockefeller Communications Group, apoiado pela Fundação Rockefeller e pelo seu administrador, John Marshall. Composto por doze especialistas, entre os quais se incluem no grupo inicial Lyman Bryson, Lloyd A. Free, Geoffrey Gorer, Harold Lasswell, Paul Lazarsfeld, Robert Lynd, Charles Siepmann, Donald Slesinger, Douglas Waples, Albert H. Cantril e Ivor A. Richards ${ }^{19}$, este grupo representou uma das primeiras tentativas de estudar a comunicação de massas de uma forma sistemática, empírica e interdisciplinar (Pooley, 2008). Teve como objectivo primordial esboçar uma perspectiva teórica e analítica que permitisse à Fundação estabelecer os critérios para o futuro financiamento de projectos de investigação em comunicação. Os debates tiveram lugar em Nova lorque, entre setembro de 1939 e junho de 1940, e deles resultaram 30 documentos de trabalho, dois memorandos (dezembro de 1939 e julho de 1940) e um relatório final, que é por alguns considerado o texto fundador da pesquisa interdisciplinar em comunicação de massas nos EUA: Needed Research in Communication (October 1940, RAC 200, 200R/224/2677) (Bryson e outros, 2004)20.

O documento, produzido nas vésperas da entrada dos EUA na II Guerra Mundial, sugere que o governo norte-americano assuma responsabilidades no que respeita ao bem-estar dos cidadãos e à preservação da democracia. Para estes objectivos, aconselha-se aquele a investir em formas eficazes e sofisticadas de justificar as suas propostas e decisões. Por sua vez, defendese que os cidadãos possuam os melhores meios para explicar ao governo como se sentem afectados pelas suas medidas. A principal conclusão deste relatório aponta para a importância de um forte investimento na investigação, pois só desta forma seria possível transformar a comunicação num processo bidireccional. As conclusões do Rockefeller Communications Group revelam uma profunda confiança nos factos e na expertise científico-técnica para enfrentar

19 O crítico literário inglês Ivor A. Richards chegou a fazer parte deste grupo, tendo abandonado os trabalhos quando dois dos seus relatórios sobre semântica foram ignorados pelos seus pares.

20 Para um conhecimento detalhado destas discussões e dos documentos que daí resultaram, ver Gary (1996, p. 124-147) e Glander (2009, p. 41-47). 
os problemas sociais, na linha das novas orientações das ciências sociais norteamericanas.

Muitas são, no entanto, as questões difíceis sobre as quais o relatório finalé omisso. Glander sintetiza-as em quatro pontos principais: 1) quais as implicações sociais de um programa de investigação de tamanha magnitude, cujo objectivo era manufacturar o consenso; 2) o relatório nunca cruzava as diferenças ou semelhanças entre a propaganda financiada pelo Estado e a financiada pelos privados; 3) no relatório não havia a percepção de que reduzindo as políticas públicas para níveis de publicidade tal podia afectar o funcionamento do sistema democrático e as capacidades de uma alegada liberdade e autonomia individual no interior da sociedade; 4) por último, o documento não articulava os problemas a ser analisados por aquela investigação e os que não seriam desenvolvidos (Glander, 2009, p. 46-47).

Os propósitos da constituição deste grupo, assim como as conclusões a que chegou, indiciam uma correspondência entre os imperativos ligados ao esforço de guerra e a investigação em comunicação de massas. As palavras do sociólogo canadense Serge Proulx são uma síntese perspicaz a esse respeito: "o governo e os militares reclamam ajuda de especialistas em comunicação e, reciprocamente, estas solicitações governamentais contribuem para a formidável expansão do domínio das investigações aplicadas à comunicação de massas e à persuasão" (Proulx, 2001, p. 473-474).

\section{Os rumos da investigação em comunicação de massas decorrentes da entrada dos EUA na II Guerra Mundial}

Nas vésperas da II Guerra Mundial, o contexto de tensão e a eminência do conflito contribuíram para modificar substancialmente as relações entre os departamentos de ciências sociais das universidades norte-americanas e governo. Este começou a apoiar-se cada vez mais nestas ciências para orientar os objectivos políticos em tempo de guerra. Nesta sequência, foram criadas diversas instâncias governamentais (Office of Emergency Management, Coordenator of Information, Office of Strategic Services, Office of Facts and Figures e Office of War Information) que solicitavam permanentemente aos cientistas sociais informações detalhadas relativamente à moral das tropas e ao conhecimento da opinião pública (Glander, 2009).

A controvérsia em torno da utilização de mecanismos de propaganda em contextos democráticos, que marcou a vida pública norteamericana no período entre as duas Guerras, passará para segundo plano quando 
se coloca de novo a questão da participação dos EUA na II Guerra Mundial. Do ponto de vista comunicacional, a entrada no conflito é meticulosamente preparada pela administração norte-americana, cujo objectivo é alcançar o apoio da nação em redor da decisão do governo. Essa estrutura é erguida com a anuência de uma parte significativa das elites intelectuais e científicas que, contratadas pelos organismos governamentais e militares, colaboraram activamente na elaboração da estratégia de propaganda e de desinformação (a difusão de informação deformada ou falsificada de maneira premeditada) dos aliados. Verifica-se um acordo alargado entre os vários sectores intelectuais quanto ao envolvimento directo dos EUA no conflito e à importância da utilização dos mass media para informar e convencer o público norte-americano do bom fundamento desta decisão e de todas as consequências daí decorrentes. Entre estas, é importante frisar o bombardeamento de cidades e de populações civis, assim como a corrida para a construção da arma mais destruidora de todos os tempos, a bomba atómica. Este compromisso entre a elite intelectual e a elite política promoveu uma autêntica coligação entre pesquisadores interessados no tópico da comunicação.

Uma parte muito significativa dos projectos de investigação aplicada em comunicação, entre os anos de 1920 e 1940, foi largamente financiada pela administração dos EUA (governo e sector militar), por fundações, como a Rockefeller e a Carnagie, e pelo mundo empresarial21. São várias as pesquisas, quer no âmbito das ciências sociais, quer no âmbito das ciências físiconaturais, prosseguidas numa lógica de interacção estreita entre os mundos académico, político e económico, tais como são diversos os modelos teóricos e metodológicos desenvolvidos a partir deste enquadramento institucional.

No campo das ciências sociais, destacam-se os estudos conduzidos pelo já referido Lasswell, enquanto responsável da Experimental Division for the Study of Wartime Communications, sobre os conteúdos e efeitos das mensagens dos mass media. Na linha do behaviorismo ortodoxo, observavam-se os sujeitos "de fora", considerando os seus comportamentos como reacções às diversas solicitações do meio envolvente ${ }^{22}$. Desvendar as funções "naturais" e "abstractas"

21 Um dos textos que melhor discute criticamente o contexto de implementação e desenvolvimentos da pesquisa administrativa norte-americana é "Sociologia dos meios de comunicação social" de Todd Gitlin (2002). A este respeito, ver ainda Sierra Caballero (1999, p. 212).

22 É de salientar, porém, que na psicologia experimental de Wilhelm Wundt, por muitos considerado o fundador do behaviorismo, de 1879 em diante, a introspecção (o que os indivíduos diziam sobre si próprios) contava como prova científica, cetris paribus. Também pode ser citado o exemplo do supostamente behaviorista e experimentalista Clark L. Hull, um influente psicólogo norte-americano que, nos anos de 1940, combinava essa orientação com um grande interesse pela psicanálise. Devo esta precisão aos comentários que Hermínio Martins fez a este trabalho. 
que mantinham a ordem social era, em sentido lato, a proposta deste modelo de pesquisa e dos projectos que começaram a hegemonizar a investigação da comunicação de massas. A voga deste estilo de estudos marcou profundamente a pesquisa sobre opinião pública e media nos EUA. Talvez se possa afirmar que, tal como escreve Paul Beaud (1984), esta opção condicionou todas as etapas, variantes e sofisticações teóricas e empíricas da mass communication research norte-americana:

\begin{abstract}
Desde as suas origens metodológico-teóricas, a investigação sobre comunicação de massas conservou uma atracção preponderante pela problemática dos efeitos. Quaisquer que sejam as suas manifestações sucessivas, desde o modelo primitivo da agulha hipodérmica (o que os media fazem às pessoas) à aproximação da abordagem dos 'usos e das gratificações' (o que as pessoas fazem com os media), a problemática dos efeitos permaneceu o eixo central da maioria das publicações deste domínio, a justificação da sua pretensão à cientificidade, o argumento principal que sustenta o seu empirismo, escoando fundos públicos e privados que se the consagram, confortando-os no seu papel de engenheiros sociais (Beaud, 1984, p. 53-54).
\end{abstract}

Não negligenciando a sua diversidade, são vários os programas desenvolvidos no quadro deste estilo de pesquisa: as investigações "empíricoexperimentais da'persuasão',' projecto que monitorizava o moral da tropa, de Carl Hovland, Director da Research Branch of Information and Education Division, do Departamento de Guerra norte-americano; as pesquisas sociológicas empíricas sobre a capacidade de persuasão da comunicação de massas desenvolvidas sob a liderança de Paul Lazarsfeld ${ }^{23}$ e Robert Merton ${ }^{24}$; a elaboração da hipótese dos "usos e das gratificações" de Herta Herzog; e, mais tarde, os trabalhos de Wilbur Schramm sobre a avaliação dos efeitos das campanhas presidenciais norteamericanas na população.

Estas pesquisas desenvolveram-se teoricamente em redor do objectivo da integração funcional dos processos informativos no conjunto do sistema social,

23 Lazarsfeld foi uma figura marcante na introdução das metodologias quantitativas nas ciências sociais. Trabalhou no âmbito da pesquisa em comunicação e media com Robert Merton, uma das figuras mais destacadas da sociologia norte-americana daquele período. Ambos procuraram distanciarse das perspectivas mais redutoras do estudo da propaganda, propondo o conceito de "propaganda de facto"como alternativa à propaganda que procurava influenciar pelas emoções. De todas as formas, os dois sociólogos manifestaram esperança que a propaganda pudesse ser conduzida eticamente e que a ciência poderia ser uma preciosa ajuda nesse esforço. Sobre este tópico, ver Simonson (2010).

24 Merton tinha uma visão sociológica pluralista onde se pressentem as influências de Karl Marx, Émile Durkheim e Kenneth Burke, entre outros. 
através, quer da análise das chamadas funções e disfunções comunicativas, quer ainda das supostas conexões estruturais e funcionais da comunicação com os diferentes subsistemas da sociedade, como a educação, a família, a economia e a política. Esta visão teórica não incorporou o papel dos media na comunicação pública enquanto força de construção simbólica e política do mundo, ou quando a percebeu tendeu a ver esse papel num plano que se articulava com uma ideia de mudança social como sinónimo de progresso ${ }^{25}$. O desenvolvimento destas tendências de investigação encontrou no mercado e na procura da esfera produtiva um forte incentivo, contrastando com a realidade europeia, onde os sistemas de comunicação implantados eram maioritariamente públicos, o que significava menor pressão publicitária e maior regulação do sector ${ }^{26}$.

Não se pode, no entanto, restringir a compreensão das razões que conduziram à pesquisa sistemática da comunicação de massas apenas aos seus factores contextuais, por mais que se admita a sua importância. Um outro elemento decisivo residiu na circunstância de que a sensibilidade epistemológica predominante das ciências sociais dos EUA enveredou por uma tendência em que o conhecimento social, para alcançar o estatuto de ciência, deveria orientar-se segundo o ideal de cientificidade praticado nas ciências naturais. Os entendimentos e as análises da comunicação e dos media, sob esta perspectiva epistemológica, estimularam as possibilidades de mensuração dos fenómenos sociais e emprestaram à investigação dos processos comunicativos um carácter aplicado com estreita relação com o contexto militar da época (que se prolongou, de um outro modo, com a Guerra Fria) e o posterior impulso para uma sociedade de consumo, incluindo aqui as mercadorias da indústria cultural.

\section{Conclusão}

Um dos pressupostos do presente artigo baseia-se na relação entre os valores epistémicos internos e os valores externos ético-sociais que intervêm nas opções dos pesquisadores e nos resultados obtidos. Esta relação é certamente complexa e não se defende aqui que os valores externos determinam totalmente

25 Secundamos as palavras que Sierra Caballero escreve a este respeito: “Este enquadramento teórico negará, por omissão, a função dos meios de comunicação pública como máquinas administrativas e a actividade dos sistemas, dispositivos e hierarquias institucionais de mediação como formas materiais da organização da hegemonia, na tutela do controlo social da comunicação pública moderna. Como sistema teórico de pensamento sobre a informação e a comunicação parte da ideia do desenvolvimento da modernidade, como um processo de planeamento da mudança social em ordem ao progresso" (1999, p. 211).

26 Enric Saperas elucida esta questão, acrescentando que esta situação só se alterou depois da II Guerra Mundial com a criação de um mercado publicitário europeu plenamente desenvolvido e a implementação progressiva dos modelos comerciais de rádio e televisão (1992, p. 20). 
ou têm o mesmo peso em todas as fases da investigação. É verdade, todavia, que a sociologia e a filosofia da ciência das últimas décadas mostram um quadro de forte condicionamento mútuo. A investigação não decorre em nenhuma torre de marfim, por mais autónoma, imparcial e abrangente que pretenda ou consiga ser.

A actividade científica é composta por várias fases e se, nalguma delas predominam os valores eminentemente cognitivos, como ocorre no momento do exame das teorias e das hipóteses, noutras fases, em particular na escolha da estratégia de investigação, na selecção dos objectos e na aplicação do conhecimento científico, os valores ético-sociais e os propósitos comerciais e políticos dos financiadores das pesquisas podem desempenhar um papel destacado.

Como se tentou ilustrar, não foram apenas muitos dos cientistas da física nuclear, para referir um exemplo da II Guerra Mundial como o da corrida à bomba atómica, que se prestaram ou adequaram a sua pesquisa às exigências bélicas (e num outro plano há que referir também as de mercado). Ao longo do texto, discutiu-se como o contexto de guerra favoreceu certas estratégias de investigação e estilos de pesquisa no âmbito dos estudos de comunicação e media. Compreender a pesquisa não só no plano teórico, mas também nas interacções entre o teórico e o contextual tem uma grande importância. A este respeito, num outro âmbito, Marialva Barbosa (2013) afirma adequadamente que a história da comunicação nos países do Sul é sempre perspectivada a partir dos contextos do Norte.

Nas duas guerras mundiais foi necessário conquistar o apoio popular e modelar a opinião de cada nação. Hannah Arendt, na sua discussão acerca da diferença entre os conceitos de poder e violência, argumenta que o poder político, mesmo dos governos tiranos, e ainda mais dos governos democráticos, necessitam da força da opinião; e que esta é a força do número daqueles que consentem ou aderem activamente a uma certa causa ou decisão. Arendt é clara sobre a relevância da anuência e aprovação da população tão mais importante quando se trata de mobilizar uma nação para a guerra:

É a adesão do povo que confere poder às instituições de um país, e esta adesão não é mais do que a continuação do consentimento que foi de início a origem das leis. Sob as condições de um governo representativo, considera-se que o povo comanda aqueles que 0 governam (Arendt, 2014, p. 46-47). 
Apoiar-se na e manietar a credulidade da população, levá-la ao engano, constrangê-la a agir mesmo que o engano e a acção tenham como justificação o fim de lutar contra, na I Guerra Mundial, as nações inimigas, e na II Guerra Mundial, derrotar o nazismo, foi a orientação que inaugurou a época da produção mediática e industrial da propaganda e da falsidade, e que não mais cessou num mundo em que as guerras se têm expandido (Guerra Fria, Guerra do Vietname, do Iraque, Afeganistão, Síria, Ucrânia, etc.). Mas esconder a verdade ao povo, enganá-lo mesmo que seja para a seu suposto bem, mostrou também os impasses e os erros de muitos sonhos liberais, incluindo o liberalismo radical e socializante de Dewey, que não conseguiram pensar aprofundadamente o tópico do conflito ou mostraram imensa ingenuidade para com a força penetrante dos media e das tecnologias modernas. Pensar que meios de comunicação poderosos do ponto de vista da influência social ou, pior ainda, que a propaganda pode ser bem usada, conduzem frequentemente ao esquecimento das terríveis consequências que aquelas estimulam.

Se é verdade que o uso da propaganda, da manipulação e da desinformação, no período entre as Guerras Mundiais, quer por governos autoritários, quer por governos democráticos, promoveu a reflexão teórica sobre este tópico, tal não significa que, alteradas as circunstâncias políticas e militares, aquelas técnicas tenham desaparecido e muito menos deixado de ser objecto de reflexão académica, bem pelo contrário. De então para cá, mesmo assumindo que as sociedades ocidentais se autodefinem como democráticas, transparentes e racionais, o peso destas técnicas não mais cessou de se fazer sentir na vida social, constituindo-se como uma ameaça grave aos regimes democráticos.

Praticamente sem resistência e com o auxílio de tecnologias cada vez mais sofisticadas de disseminação de mensagens à distância, as formas de manipulação da opinião e da palavra invadem e reconfiguram hoje praticamente todos os domínios da vida política, social, comercial (publicidade e relações públicas), artística e até a esfera das relações interpessoais. Assim, é mais do que compreensível que, embora já não sob os mesmos pressupostos behavioristas, entretanto ultrapassados nos estudos comunicacionais, e de concepções mecanicistas dos seres humanos, nas últimas décadas, o debate entre os teóricos sociais não mais deixou de prosseguir (Packard, 1957; Breton, 1999; Winner, 2013). 


\section{Referências}

ALVES, Artur. Jacques Ellul's ,Anti-Democratic Economy': Persuading Citizens and Consumers in the Information Society. TripleC, 12(1), p. 169-201, 2014. Disponível em : http://www.triple-c.at.

ARENDT, Hannah. Sobre a Violência. Lisboa: Relógio d'Água, 2014.

BAILLARGEON, Normand. Préface. Edward Bernays et l'invention du gouvernment invisible. In: BERNAYS, Edward. Propaganda. Comment manipuler l'opinion en democratie. Paris: Zones, 2007, p. 5-25.

BARBOSA, Marialva. História da comunicação no Brasil. Petrópolis: Vozes, 2013.

BEAUD, Paul. La société de connivence: Media, mediations et classes sociales. Paris: Aubier, 1984.

BERGANZA CONDE, Maria Rosa. A contribuição de Robert E. Park, o jornalista que se converteu em sociólogo, à teoria da informação. In: BERGER, Christa e MAROCCO, Beatriz (org.). A era glacial do jornalismo. Teorias sociais da imprensa. Vol. I. Porto Alegre: Editora Sulina, 2008, p. 15-32.

Comunicación, opinión pública y prensa en la sociologia de Robert E. Park. Madrid: CIS, 2000.

BLUMER, Herbert. Suggestion for the study of mass-media effects. In: Symbolic interactionism. Perspective and method. Berkeley, Los Angeles e Londres: University of California Press, 1998a, p. 183-194.

Public opinion and public opinion polling. In: Symbolic interactionism. Perspective and method. Berkeley, Los Angeles e Londres: University of California Press, 1998b, p. 195-208.

BRAMAN, Sandra. Communication researchers and policy-making. Cambridge: The MIT Press, 2003.

BRETON, Philippe. A manipulação da palavra. São Paulo: Edições Loyola, 1999.

BRYSTON, Lyman e outros. Needed research in communication. In: PETERS, John D. e SIMONSON, Peter (eds.). Mass communication and American social thought. Keys texts, 1919-1968. Lanhan, Boulder, Nova lorque, Toronto e Oxford: Rowman \& Littlefield Publishers, 2004, p. 136-138.

BYBEE, Carl. Can democracy survive in the post-factual age? A return to LippmannDewey debate about the politic of news. Journalism \& Mass Communication Monographs, 1, no 1, p. 27-66, 1999. 
CAREY, James W. The Chicago School and the history of mass communication research. In: MUNSON, Eve S. e WARREN, Catherine. A. (eds.). James W. Carey. A critical reader. Minneapolis e Londres: University of Minnesota Press, 1997, p. 14-33.

A cultural approach to communication. In: Communication as culture. Essays on media and society. Nova lorque e Londres: Routledge, 2009, p. 1128.

CMIEL, Kenneth. On cynism, evil, and discovery of communication in the 1940's. Journal of Communication, v. 46 (3) (Verão), p. 88-107, 1996.

CZITROM, Daniel. Media and the American mind: From Morse to McLuhan. Chapel Hill: University of North Carolina Press, 1992.

DOMENACH, Jean-Marie. A Propaganda política. Amadora: Livraria Bertrand, 1975.

DOOB, Leonard. W. Goebbels y sus principios propagandísticos. In: MORAGAS SPÁ, Miguel. de (ed.). Sociología de la comunicación de masas. III Propaganda política y opinión pública. Barcelona: Gustavo Gili, 1985, p. 122-153.

DORTIER, Jean-François. La publicité nous manipule-t-elle?. Sciences Humaines. Les Grands Dossier, n 22, p. 59-62, 2011.

EADIE, William F. Communication as an academic field: USA and Canada. In:DONSBACH, Wolfgang (ed.). The international encyclopedia of communication. Blackwell Publishing. Blackwell Online. 15 June 2008.

ELLUL, Jacques. Histoire de la propaganda. Paris: PUF, 1967.

. Propagandas. Uma análise estrutural. Lisboa: Antígona, 2014.

FRANÇA, Vera. R.V. e SIMÕES, Paula G. A Escola de Chicago. In: CITELLI, Adilson, BERGER, Christa., BOCCEGA, Maria A., LOPES, Maria I. V. de e FRANÇA, Vera R. V. (org.). Dicionário de comunicação: Escolas, teorias e autores. S. Paulo: Contexto, 2014, p. 170-178.

GARRETA, Guillaume. Présentation. In: DEWEY, John. Aprés le liberalism? Ses imposes, son avenir. Paris: Climats, 2014, p. 7-54.

GARY, Brett. Communication research, the Rockefeller Foundation, and mobilization for the war on words, 1938-1944. Journal of Communication, 46 (3), Verão, p. 124-148, 1996.

GITLIN, Todd. Sociologia dos meios de comunicação social. In: ESTEVES, João P. (org.). Comunicação e Sociedade. Lisboa: Livros Horizonte, 2002, p. 105-149.

GLANDER, Timothy. Origins of mass communications research during the American 
cold war. Educational effects and contemporary implications. Nova lorque e Londres: Routledge, 2009.

HARDT, Hanno. Social theories of the press: Constituents of communication research, 1840s to 1920s. Nova lorque e Oxford: Rowman \& Littlefield Publishers, 2001.

HEIL Jr., Alan L. Voice of America. Nova lorque: Columbia University Press, 2003.

JANSEN, Sue. Walter Lippmann, straw man of communication research. In: PARK, David W. e POOLEY, Jefferson (eds.). The history of media and communication research. Contested Memories. Nova lorque: Peter Lang, 2008, p. 71-112.

LASSWELL, Harold. A estrutura e a função da comunicação na sociedade. In: PISARRA, João P. Comunicação e sociedade. Lisboa: Livros Horizonte, 2002, p. 49-60.

. Propaganda technique in the World War. Nova lorque: Peter Smith, 1938.

LIPPMANN, Walter. Public opinion. Nova lorque, Londres, Toronto, Sydney e Singapura: Free Press Paperbacks, 1997.

LÓPEZ-ESCOBAR, Esteban. Cooley and his communicative theory of the social. The pioneer's inspiration. In: McCOMBS, Maxwell e ALGARRA, Manuel M. (eds.) Communication and social life. Studies in honor of Professor Esteban López-Escobar. Pamplona: Eunsa, 2012, p. 29-52.

MATTELART, Armand. História da utopia planetária. Da cidade profética à sociedade global. Lisboa: Bizâncio, 2000.

PACKARD, Vance. The hidden persuaders. Nova lorque: David McKay Co. Inc, 1957.

PARK, Robert E. The immigrant press and its control. Nova lorque: Harper \& Brothers Publishers, 1922.

PETERS, John. D. Democracy and American communication theory: Dewey, Lippmann. Lazarsfeld. Communication, 1, p. 199-220, 1989.

PETER, John D. e SIMONSON, Peter. From hope to disillusionment. Mass communication theory. Coalesces, 1919-1933. In: Mass communication and American social thought. Keys texts, 1919-1968. Lanhan, Boulder, Nova lorque, Toronto, Oxford: Rowman \& Littlefield Publishers, 2004, p. 13-20.

POOLEY, Jefferson. The new history of mass communication research. In: PARK, David. W. e POOLEY, Jefferson (eds.). The history of media and communication research. Contested memories. Nova lorque: Peter Lang, 2008, p. 43-69. 
PONSONBY, Arthur. Falsewood in wartime. Propaganda lies of the First World War. Legion for the Survival of Freedom, 1991.

PROULX, Serge. Les recherches nord-américaines sur la communication: L'institutionnalisation d'un champ d'étude. L'Année Sociologique, v. 51, n², p. 467-485, 2001.

RIBEIRO, Aquilino. É a guerra. Lisboa: Bertrand Editores, 2014.

RÜDIGER, Francisco. As relações públicas e o debate sobre a propaganda no período entre-guerras. Revista Brasileira de Ciências da Comunicação, v.37 (1), p. 4570, Jan./Jun. 2014.

RUSSIL, Chris. Through a public darkly: Reconstructing pragmatist perspectives in communication theory. Communication Theory, no 18, p. 478-504, 2008.

SAPERAS, Enric. La sociología de la comunicación de masas en los Estados Unidos. Una introducción crítica. Barcelona: PPU, 1992.

SCHUDSON, Michael. The 'Lippmann - Dewey debate' and the invention of Walter Lippmann as an anti-democrat 1985-1996. International Journal of communication, $\mathrm{n}^{\circ} 2$ : 1031-1042, 2008.

SIERRA CABALLERO, Francisco. Elementos de teoría de la información. Sevilha: Editorial MAD, 1999.

SILVA, Filipe C. Virtude e democracia. Lisboa: Imprensa de Ciências Sociais, 2004.

SPROULE, J. Michael. Propaganda and democracy. The American experience of media and mass persuasion. Cambridge: Cambridge University Press, 1997.

Progressive propaganda critics and the magic bullet myth. Critical Studies in Mass Communication, v. 5, p. 225-246, 1989.

. Propaganda studies in American social science: the rise and fall of critical paradigm. Quarterly Journal of Speech, v. 73 (1), p. 60-87, 1987.

SUBTIL, Filipa. A abordagem cultural da comunicação de James W. Carey. Revista Brasileira de Ciências da Comunicação, v. 37 (1), p. 19-44, Jan./Jun. 2014.

. A comunicação entre a utopia e a tecnocracia: para uma fundamentação teórica das tecnologias da informação. Análise Social, v. XLI (181), p.1075-1093, 2006.

SUBTIL, Filipa e GARCIA, José L. Communication: An inheritance of the Chicago school of social thought. In: HARDT, Christopher. (ed.). The legacy of Chicago school of sociology. Manchester: Midrash Publishing, 2010, p. 216-243. 
TARDE, Gabriel. A opinião e a multidão. Mem Martins: Publicações Europa-América, 1991.

TCHAKHOTINE, Serge. El secreto del éxito de Hitler: La violencia psiquica. In: MORÁGAS SPÁ, Miguel de (ed.). Sociologia da comunicación de masas: III. Propaganda política y opinión pública. Barcelona: Gustavo Gili, 1985, p. 154-191.

TÖNNIES, Ferdinand. Opinião pública. In: MAROCCO, Beatriz. e BERGER, Christa (org.). A era glacial do jornalismo. Teorias sociais da imprensa. vol. I. Porto Alegre: Editora Sulina, 2006, p. 83-93.

. Opinião pública e 'a' opinião pública. In: MAROCCO, Beatriz e BERGER, Christa (org). A era glacial do jornalismo. Teorias sociais da Imprensa, vol. I. Porto Alegre: Editora Sulina, 2006, p. 94-154.

TORREGOSA, Marta, SERRANO-PUCHE, Javier e ALGARRA, Manuel M. Comunicación como integración. Ideas para una teoría comunicativa de lo social. In: McCOMBS, Maxwell e ALGARRA, Manuel M. (eds.). Communication and social life. Studies in honor of Professor Esteban López-Escobar. Pamplona: Eunsa, 2012, p. 321337.

VARÃO, Rafiza. A propaganda como arma política: a influência de Charles Merriam na obra de Harold Lasswell. Esferas, ano 2, n³, p. 29-37, Julho-Dezembro 2013.

Harold Lasswell e o campo da comunicação. Tese de Doutoramento em Comunicação, Brasilia: Faculdade de Comunicação, Universidade de Brasilia, 2012.

WEBER, Max. Sociologia da imprensa: um programa de pesquisa. In: MAROCCO, Beatriz e BERGER, Christa (org.). A era glacial do jornalismo. Teorias sociais da imprensa. vol. 1. Porto Alegre: Editora Sulina, 2006, p. 34-44.

WINNER, L. Propaganda and dissociation from truth. In: JERÓNIMO, Helena M., GARCIA, José L. e MITCHAM, Carl. Jacques Ellul and the technological society in the 21 st century. Dordrecht: Springer, 2013, p. 99-113.

Recebido em: 15/12/2014

Aceito em: 20/1/2015

Endereço da autora:

Filipa Subtil <fsubtil@escs.ipl.pt>

Escola Superior de Comunicação Social

Instituto Politécnico de Lisboa

Campus de Benfica do IPL

1549-014 Lisboa - Portugal

Tel. (00) (351) 217119000 